\title{
Relation between Attention Deficit Hyperactivity Disorder Among School Age Children and Parent's Stress and Sense of Competence
}

\author{
Samia Salah Nagy*, Nadia Ebrahim Sayied**, Fatma Nagy Kotb***,Safaa Mohammed Zaki**** \\ *Demonstrator of Psychiatric Mental Health Nursing, Faculty of Nursing - Minia University. \\ ** Assistant Professor of Psychiatric Mental Health Nursing, Faculty of Nursing - Assuit University. \\ *** Lecturer of psychiatric Mental Health Nursing, Faculty of Nursing, Minia University. \\ $* * * *$ Lecturer of psychiatric Mental Health Nursing, Faculty of Nursing, Minia University.
}

Abstract

This study aimed to assess the relation between attention deficit hyperactivity disorder among school age children and parent's stress and sense of competence. Design: A descriptive correlational research design was utilized in this study. The study sample included one hundred parents having children with ADHD. The study was conducted at the children and adolescents outpatient clinic in Minia hospital for psychiatric health and addiction treatment. Four tools were utilized to measure the variables of the study included; child's and parents socio-demographic data, parent disruptive behavior disorder (DBD) Rating Scale, parenting stress index scale, and parent sense of competency scale (PSOC). Results: it was found that more than three quarters of the children had combined type of ADHD. More than two thirds of parents had high level of stress \& the majority of the parents were not competent. Conclusion: There were highly significant positive correlations between total ADHD and total parent's stress $(p=.007) \&$ there were highly significant negative correlations between parents sense of competence and total parent's stress. Recommendations: Counseling clinics for parents of ADHD children are needed to; ensure an effective parents response to the needs of ADHD children, increase awareness, coping, competence and to decrease parent's stress.

Keywords: ADHD- parent's stress - sense of competence

\section{Introduction}

Attention deficit hyperactivity disorder (ADHD) is the most common neurobehavioral disorder of childhood characterized by persistent hyperactivity, impulsivity and inattention and it considers one of the leading diagnosed disorders in school age children around the world; it affects children and can continue into adulthood(1). The symptoms of ADHD are present for six months or more to a degree that is much greater than others of the same age and cause problems in at least two settings (such as school, home, or recreational activities) in order to receive a diagnosis of ADHD (2).

ADHD is thought to be the result of complex interactions between genetic, environmental and neurobiological factors. The Diagnostic and Statistical Manual of Mental Disorders (DSM -5) indicated that there are three subtypes of ADHD of which an individual can be classified into predominantly inattentive type, predominantly hyperactive-impulsive type and combined type. (3) The effects of ADHD are not confined to the individual alone but go beyond and can affect his/her immediate social context, especially the school and family context. (4)

The demands of parenting are usually associated with some stress and elevated levels of stress may affect the parent-child relationships and parenting practices. This is especially the case of families have children with special needs conditions or disorders like ADHD. (5) Moreover, parent caregiver experience is impacted by the needs, expectations and distress of a child with ADHD. As primary caregiver parents of children with ADHD face two major challenges: caring for their child with disabilities, which includes management of problematic behavior and balancing their own stress while overseeing the well-being of the rest of the family. (6)

Parental sense of competence is related to specific parenting behaviors, great breadth of knowledge regarding child development and are more likely to express flexible, less authoritarian child-rearing beliefs and great use of proactive techniques to handle child behaviors and less use of punitive responses. (7) Moreover, parents' perceptions of their roles as parents significantly impacts their interactions with their children. (8) Children with ADHD makes parent's hard to concentrate, also make them feel irritable, restless and might have more trouble controlling their temper, planning things out, or sticking to a schedule. All these things may affect their roles as parents and their sense of competence (9).

Nurses have an important role in relation to parents with a child who has ADHD. They are responsible for revealing early signs of special needs in children to follow-up and give support to those children and their parents. Nurses observe, assess and interact with the child and parents to collect the data needed to establish an accurate mental health diagnosis (10).

\section{Significance of the Study}

Attention-deficit/hyperactivity disorder (ADHD) is a common neurobehavioral condition which affects $5 \%$ to $10 \%$ of the pediatric population worldwide. The rate of prevalence is $11 \%$, and has increased throughout even recent years-from $7.8 \%$ in 2003 to $9.5 \%$ in 2007 and to $11.0 \%$ in 2012 . This involves an increase of $3 \%$ per year since 1997. (11) In Egypt, few studies investigated the epidemiology of ADHD, the reported prevalence of ADHD among primary school children ranged between $6.5 \%$ and $8 \%$ in Menoufia Governorate (12), the overall prevalence of ADHD was $6.5 \%$ in Minia Governorate among sample of school children (ages: 4 to 12 years) (13).

The children of ADHD have aggressive behaviors contribute to diminish academic and social functioning and its impact on quality of life for their families. Parents with children of ADHD feel aggression and violence toward these negative behaviors and the demands of their children. The family need emotional support and must make adjustment to care for their needs; modifying their behaviors and performing daily living activities toward their children. So, this study aimed to assess relationship between attention deficit hyperactivity disorder among school age children and parent's stress and sense of competence. 
Aim of the Study

This study aimed to assess the relation between attention deficit hyperactivity disorder among school age children and parent's stress and sense of competence.

\section{Research Questions:}

- What is the strength of the relationship between ADHD and parent's stress?

- What is the strength of the relationship between ADHD and sense of competence?

- Is there a relation between parent's stress and sense of competence?

\section{Subjects and Method:}

Research Design

A descriptive correlational research design was used in this study.

\section{Research Setting:}

This study was conducted at the children and adolescent outpatient clinic of Minia hospital for psychiatric health and addiction treatment .The outpatient clinic works two days per week (Monday, and Wednesday from 9 am to $12 \mathrm{pm})$. The hospital serves Minia governorate and its districts.

Sample

A convenience sample of 100 children and their parents were included in the study.

\section{Inclusion Criteria}

- For parents:-

○ Both Gender.

- Parents having children with ADHD.

○ Parents agree to participate in the research.

- For children:-

○ Age of child ranges from (6-12) year.

$\circ$ All children diagnosed with all types of ADHD by the psychiatrist responsible for treatment using Diagnostic and Statistical Manual of Mental Disorders (DSM 5) as diagnostic criteria.

\section{Exclusion Criteria:-}

- For parents: - Signs of major medical condition, mental retardation, psychosis, and bipolar disorder.

- For children:-

- Children who were diagnosed as (mentally retarded, autistic disorders, conduct, oppositional and deviant disorder) would be excluded from the study.

\section{Data collection tools:-}

in this study.

The following tools were utilized for collecting data

1-A Structured Interviewing Questionnaire: It was developed by the researcher and revised by supervisors which divided into two parts include data about ADHD children and their parents.

Part I: personal data of parents: such as parents age, gender and level of education, occupation, family history, family size and residence.

Part II: personal data of child: such as child age, gender, school grade and child's behavior with family.
2-Parent disruptive behavior disorder (DBD) Rating Scale (Mainly for ADHD)

Parent disruptive behavior disorder (DBD) Rating Scale (Mainly for ADHD) it was developed by Pelham (1992). It contains 45 items for (ADHD, conduct disorder, oppositional disorder). The researcher selected 18 items to assess of inattention type; hyperactivity type and combined type of ADHD. This scale includes inattention symptoms 9 items six or more items must be endorsed on the parent DBD to meet the criteria for diagnosis of AttentionDeficit/Hyperactivity Disorder Predominantly inattention Type. Impulsivity / Over activity symptoms 9 items six or more items must be endorsed on the parent DBD to meet the criteria for diagnosis of Attention-Deficit/Hyperactivity Disorder Predominantly Hyperactive-Impulsive Type.

If 6 or more items are endorsed for AttentionDeficit/Hyperactivity Disorder - inattention type and 6 or more items are endorsed for Attention Deficit/Hyperactivity Disorder-hyperactivity/impulsivity type, then criteria is met for Attention Deficit/Hyperactivity Disorder, Combined Type. The scoring system was as the following 4-point likert scale. Not at all $=0$, Just a Little $=1$, Pretty Much $=2$, and Very much $=3$, scores of the items sum -up. Total score for (DBD) ranged from (0-54), Low level ranged from (0-18), moderate level ranged from (18-36) and high level ranged from (37-54). (14)

\section{3-Parenting Stress Index -short form scale (PSI/SF)}

It was developed by (Abidin, 1995) and utilized to measure stress associated with parents of children with Attention Deficit Hyperactivity Disorder younger than 12 years of age. It was composed of 36-items with three subscales. Each item was rated on a 5-point Likert-type scale anchored by 1 Strongly Disagree" to 5 = "Strongly Agree". It contains three subscales (parental Distress subscale 12 items, Parent-Child Dysfunctional Interaction subscale 12 items, and Difficult Child subscale 12 items. The total score for (PSI/SF) ranged from (36-180) ،Low level ranged from (36$84)$, moderate level ranged from (85-132) and high level ranged from (133-180). (15)

\section{4-Parent Sense of Competency Scale (PSOC)}

Parent Sense of Competency Scale was developed by (wellston 1978). The PSOC consisted of 17 items. Each item was rated on a 6 point Likert scale anchored by $1=$ "Strongly Disagree" to $6=$ "Strongly Agree. Nine (9) items on the PSOC are reverse coded. System score ranged from (17-102). A higher score indicates a higher parenting sense of competency (60-102), Low score indicates Low parenting sense of competency (17-59). (16)

\section{Content Validity}

These tools were translated into Arabic language and the content validity of the translated tools were checked and back translation technique was done by five panels of experts in psychiatric nursing to test the content validity of the tools (Assuit and Cairo Universities, Faculty of Nursing, Psychiatric Nursing department) and the necessary modifications were done.

Reliability
\begin{tabular}{|c|c|}
\hline Tools & Cronbach's alpha \\
\hline ADHD & 0.93 \\
\hline Parenting stress index scale & 0.82 \\
\hline Parent sense competency scale & 0.95 \\
\hline
\end{tabular}


Internal consistency was measured to identify the extent to which the items of tools measure the same concept and the extent to which the items are correlated with each other. Internal consistency estimated reliability by Cronbach's alpha coefficient. Cronbach's alpha coefficient of 0.00 indicated no reliability and a coefficient of 1.00 indicates perfect reliability.

\section{Pilot Study}

Pilot study was conducted on 10 parents having children with ADHD (10\%) who met the inclusion criteria to investigate and ensure the feasibility, objectivity, applicability, clarity and adequacy of the study tools and to determine possible problems in the methodological approach or tool. The results of the pilot study used to test the proposed statistical and data analysis methods. The tools were completed without difficulty, adding support to the validity of the instrument. The time needed to complete the tool was 30-45 minutes according to the needed explanation. No modifications were done in the study tools based on the pilot study and the sample was included to the total study sample.

\section{Methods of data collection}

An official permission was granted from the dean of the faculty of nursing Minia University directed to the head of psychiatric health and addiction treatment at Minia Hospital. Children with ADHD and their parents were interviewed and oral consent was obtained on individual basis to explain the nature and purpose of the study. A structured interview was conducted in one room of the outpatient clinic; questions were asked and recorded by the researcher. Measures were taken to protect patient's ethical rights. Data were collected by using a socio-demographic data sheet, Parenting Stress Index (PSI) and ADHD Symptoms Checklist, The researcher was available at the outpatient unit 2 days per week (Monday, and Wednesday from $9 \mathrm{pm}$ to $12 \mathrm{pm}$ ). The researcher conducted interviews with all Children with ADHD and their parents and collected data from them; interview taken about 30-45 minutes depending on the degree of understanding and responses of the respondent. Data collection was conducted over a six months' period extending from March 2018 till Augusts 2018.

Each parent was interviewed individually, after explaining the purpose of the interview and getting agreement of the mother to participate in the research. The researcher assured the voluntary participation and confidentiality to each subject who agreed to participate. The questionnaires were read, explained to the studied sample and the responses were recorded by the researcher for eliminating the systematic error and for more validation of the parent's information, the child's files were revised to help in completion of the needed information.

\section{Ethical consideration}

A written initial approval was obtained from the research ethical committee of the Faculty of Nursing, Minia University. Oral informed consent was obtained from the parents after explaining the nature and benefits of the study. Each assessment sheet was coded and patient's name was not appearing on the sheets for the purpose of privacy and confidentiality. Children and their parents were assured that they could withdraw at any time from the current study without any effect on their treatment and care.

\section{Statistical Analysis:}

The collected data were coded, categorized, tabulated, and analyzed using the Statistical Package for the Social Science (SPSS 20.0). Data were presented using descriptive statistics in the form of percentages, frequency, mean and standard deviation. Inferential statistical tests of significance such as Friedman's ANOVA, Pearson correlation, and independent t-test were used to identify group differences and the relations among the study variables. Level of significance at $p<0.05$ was used as the cut off value for statistical significance.

\section{Results}

Table (1):- Socio-demographic characteristics of the parents having children with ADHD (n=100).

\begin{tabular}{|c|c|c|}
\hline Characteristics & $(\mathrm{N}=100)$ & $\%$ \\
\hline \multicolumn{3}{|c|}{ Age / years } \\
\hline$-20-30$ years & 26 & 26.0 \\
\hline$-31-40$ years & 45 & 45.0 \\
\hline$-<41$ years & 29 & 29.0 \\
\hline \multicolumn{3}{|c|}{ Educational level } \\
\hline Illiterate & 48 & 48.0 \\
\hline Secondary school & 5 & 5.0 \\
\hline Preparatory school & 42 & 42.0 \\
\hline University & 5 & 5.0 \\
\hline \multicolumn{3}{|c|}{ Family number } \\
\hline $1-3$ & 6 & 6.0 \\
\hline $4-6$ & 79 & 79.0 \\
\hline $7-10$ & 15 & 150 \\
\hline \multicolumn{3}{|c|}{ History of disease } \\
\hline present & 23 & 23.0 \\
\hline Not present & 77 & 77.0 \\
\hline \multicolumn{3}{|c|}{ Residence } \\
\hline Rural & 83 & 83.0 \\
\hline Urban & 17 & 17.0 \\
\hline
\end{tabular}


Table (1): showed that, less than half $(45 \%)$ of the parents were at the age group from $31-40$ years and more than three quarters of them $(79 \%)$ had 4-6 of the family number. Also, this table presented that (48\%) of the parents were illiterates. In addition, most of the studied sample (77\%) didn't have past history of attention deficits hyperactivity disorders and the majority $(83 \%)$ of them live in rural area.

Table (2):- Socio-demographic data of ADHD child ( $\mathrm{N}=100)$.

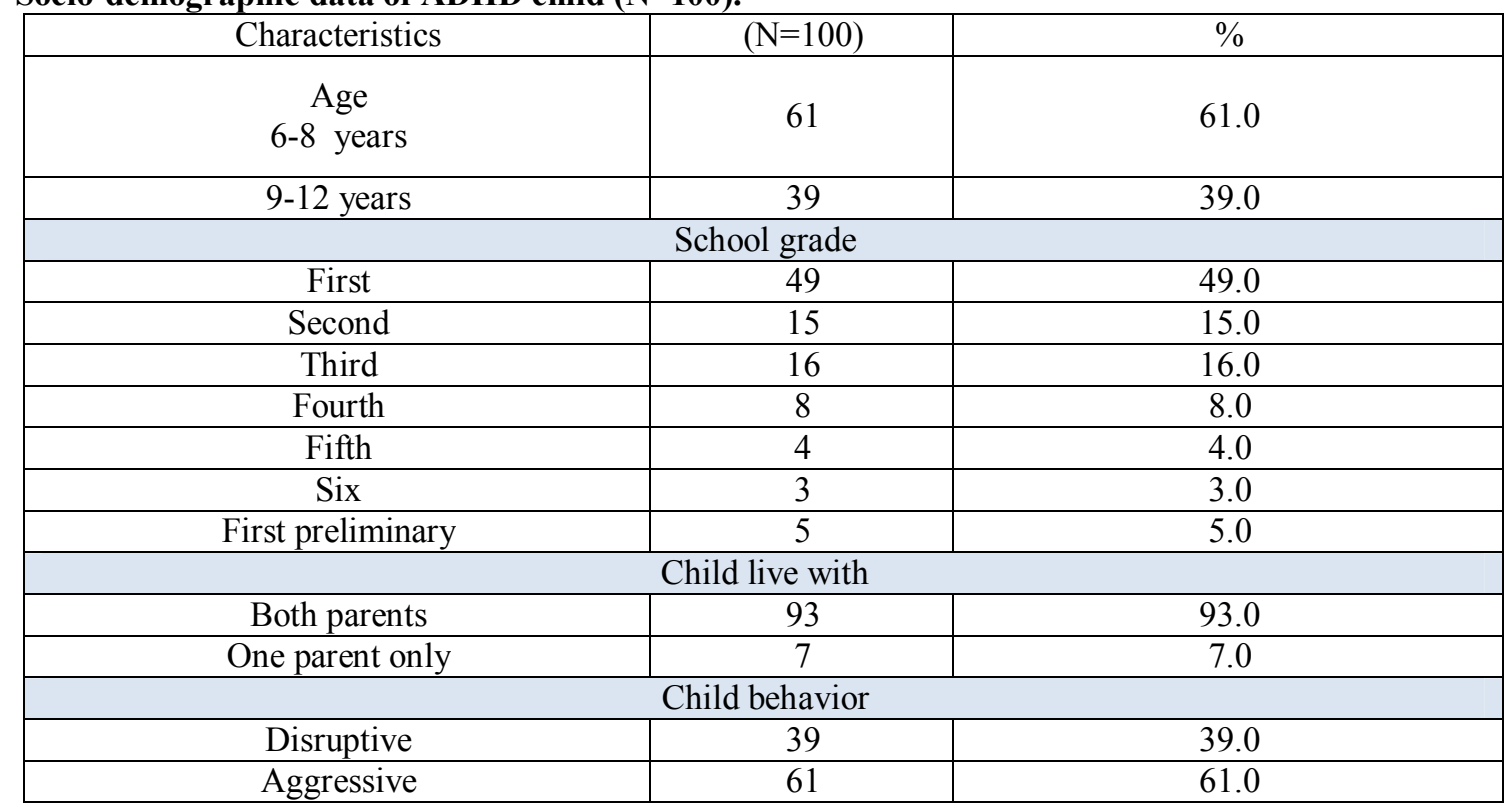

Table (2):- demonstrated that, more than half (61\%) of children with ADHD were at the age group from $6-8$ years. Also, this table showed that less than half (49\%) of them were in the first school grade and only (3\%) of them were in six school grade. In addition, the majority of the study sample (93\%) lived with both parents, and (61\%) of them had aggressive behaviors.

Table (3): Frequency distribution of ADHD level among children $(\mathrm{N}=100)$

\begin{tabular}{|c|c|c|c|c|c|c|c|}
\hline \multirow{2}{*}{$\begin{array}{c}\text { Types of ADHD } \\
\text { Level of ADHD }\end{array}$} & $\mathrm{N}$ & $\%$ & $\mathrm{~N}$ & $\%$ & $\mathrm{~N}$ & $\%$ & \multirow{2}{*}{ Mean +SD } \\
\cline { 2 - 8 } & & & & & & & \\
\hline 1-Inattention type & 3 & $42.9 \%$ & 4 & $57.1 \%$ & 0 & 0 & $9.00+4.00$ \\
\hline 2-Hyperactivity type & 0 & 0 & 9 & $60 \%$ & 6 & $40 \%$ & $9.80+3.01$ \\
\hline 3-Combined type & 6 & $7.7 \%$ & 12 & $15.4 \%$ & 60 & $76.9 \%$ & $29.71+7.33$ \\
\hline
\end{tabular}

Table (3) demonstrated that, more than three quarters of the children (76.9\%) had high level of ADHD according to the combined type. While $(60 \%)$ had moderate level according to hyperactivity type. In addition, $(57.1 \%)$ had moderate level according to inattention type.

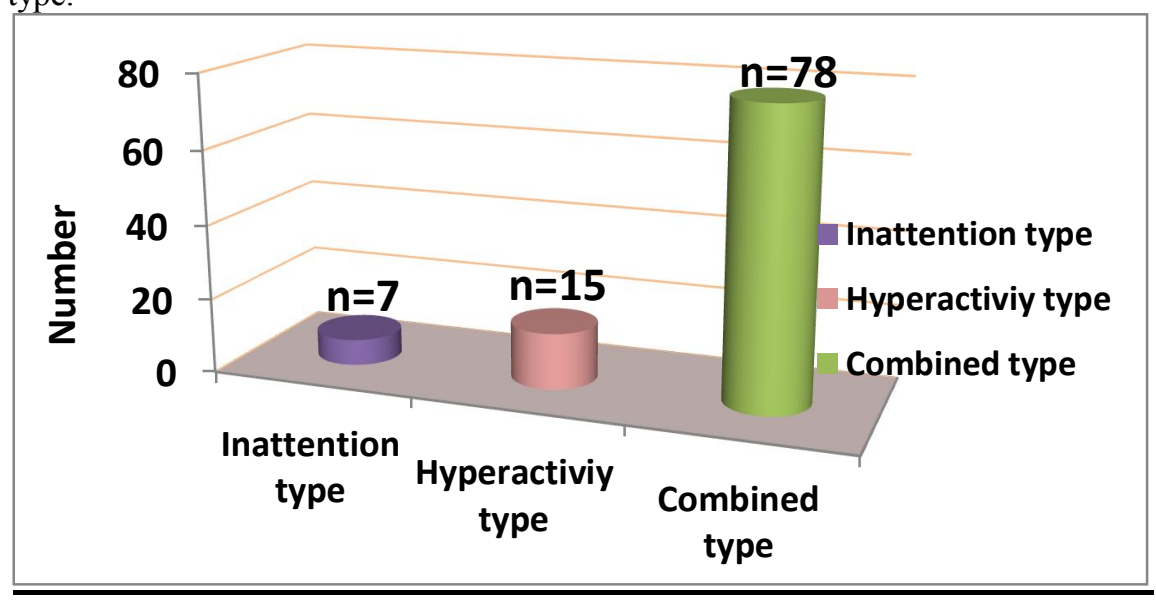

Figure (1): Types of ADHD

Figure (1) showed that, more than three quarters of the children had combined type of ADHD (78\%). 
Minia Scientific Nursing Journal (Print) (ISSN 2537-012X) Vol. (4) No. (1) December 2018

Table (4): Differences between ADHD and parents socio-demographic characteristics (N=100)

\begin{tabular}{|c|c|c|c|c|c|}
\hline \multirow[b]{2}{*}{ Variable } & \multicolumn{5}{|c|}{ ADHD } \\
\hline & $\mathrm{N}$ & $\mathrm{N} 0 \%$ & Mean + SD & $\mathrm{t}$ & $\mathrm{P}$ \\
\hline -Gender & $\begin{array}{c}\text { Male } \\
\text { Female }\end{array}$ & $\begin{array}{l}T \div \% \\
7 \leqslant \%\end{array}$ & $\begin{array}{l}7.15 \pm 23.1 \\
9.10 \pm 28.7\end{array}$ & 3.22 & $.002 *$ \\
\hline -Job & $\begin{array}{c}\text { Work } \\
\text { Not work }\end{array}$ & $\begin{array}{l}r . \% \\
\wedge . \%\end{array}$ & $\begin{array}{l}6.09 \pm 25.7 \\
9.42 \pm 27.1\end{array}$ & 0.56 & 0.57 \\
\hline - History of disease & $\begin{array}{c}\text { present } \\
\text { Not present }\end{array}$ & $\begin{array}{l}r \Psi \% \\
Y \vee \%\end{array}$ & $\begin{array}{l}7.89 \pm 31.3 \\
8.69 \pm 25.3\end{array}$ & 2.97 & $0.004 * *$ \\
\hline - Residence & $\begin{array}{l}\text { Rural } \\
\text { Urban }\end{array}$ & $\begin{array}{l}\text { Ar\% } \\
1 \vee \%\end{array}$ & $\begin{array}{l}8.87 \pm 26.3 \\
8.66 \pm 28.8\end{array}$ & 1.09 & 0.278 \\
\hline
\end{tabular}

\section{Statistically significant difference $(* P$ value $<0.01)$}

Table (4) revealed that, there were statistically significant differences between gender and history of disease regarding ADHD $(\mathrm{P}=.002 \& 0.004$ respectively) and it was observed that, the highest mean score of ADHD was among females $(9.10 \pm$ 28.7).

Table (5) :Frequency distribution of parent's stress regarding to the level of the parenting stress index $(\mathrm{N}=100)$

\begin{tabular}{|c|c|c|c|c|c|c|c|}
\hline $\begin{array}{c}\text { Subscales of parenting } \\
\text { stress }\end{array}$ & $\mathrm{N}$ & $\%$ & $\mathrm{~N}$ & $\%$ & $\mathrm{~N}$ & $\%$ & \multirow{2}{*}{ Mean \pm SD } \\
\cline { 2 - 9 } & & & & & & \\
\hline Levels of parent stress & 0 & 0 & 28 & 28.0 & 72 & 72 & $45.6 \pm 6.40$ \\
\hline 1-Parental Distress subscale & 0 & 0 & 31 & 31.0 & 69 & 63.0 & $45.5 \pm 6.32$ \\
\hline 2-Child Dysfunctional Interaction subscale & 0 & 0 & 30 & 30.0 & 70 & 65.0 & $46.1 \pm 6.33$ \\
\hline 3-Difficult Child subscale & 0 & 0 & 89 & $32.3 \%$ & 211 & $70.3 \%$ & $137.3 \pm 5.32$ \\
\hline
\end{tabular}

Table (5): demonstrated that, more than two thirds (70.3\%) of the parents had high level of stress.In addition the total mean score of the parenting stress index scale was $(137.3+5.32)$. While, only $(28 \%)$ of them had a moderate level of stress and the mean score was $(45.6+6.40)$.

Table (6): Differences between parent's stress and parent socio-demographic characteristics $(\mathbf{N}=100)$

\begin{tabular}{|c|c|c|c|c|c|}
\hline \multirow{2}{*}{ Variable } & \multicolumn{5}{|c|}{ parent's stress } \\
\cline { 2 - 6 } & $\mathrm{N}$ & NO\% & Mean + SD & T & P -value \\
\hline Gender & Male & $36 \%$ & $15.9 \pm 128.7$ & 3.91 & $0.000^{* *}$ \\
& Female & $64 \%$ & $17.2 \pm 142.1$ & & \\
\hline Job & Work & $20 \%$ & $15.7 \pm 128.7$ & 2.51 & $0.013^{*}$ \\
& Not work & $80 \%$ & $17.4 \pm 139.4$ & & \\
\hline History of disease & present & $23 \%$ & $14.3 \pm 138.7$ & .443 & 0.659 \\
& Not present & $77 \%$ & $18.4 \pm 136.8$ & & \\
\hline Residence & Rural & $83 \%$ & $18.7 \pm 136.6$ & 0.798 & 0.427 \\
& Urban & $17 \%$ & $9.95 \pm 140.4$ & & \\
\hline
\end{tabular}

\section{*P $\mathbf{P}<0.01$ Significant $\quad * * \mathbf{P}<0.001$ highly significant}

Table (6) showed that, there were highly statistically significant differences between parent's gender and job regarding parent's stress ( $\leq 0.000 \& 0.013$ respectively). While, it was observed that the highest total mean score was among female parents $(15.9 \pm 142.1)$, not working parents $(17.4 \pm 139.4)$, parent with history of ADHD (14.3 \pm 138.7$)$ and parents living in urban area was $(9.95 \pm 140.4)$.

Table (7): Frequency distribution of parents competence regarding to level of the parents sense of competence (N=100).

\begin{tabular}{|c|c|c|c|c|c|}
\hline \multirow{2}{*}{ Items } & \multicolumn{2}{|c|}{ Not competent } & \multicolumn{2}{|c|}{ Competent } & \multirow{2}{*}{ Mean \pm SD } \\
\cline { 2 - 5 } & $\mathrm{N}$ & $\%$ & $\mathrm{~N}$ & $\%$ & \\
\hline Parent competence & 87 & $87 \%$ & 13 & $13 \%$ & $54.83 \pm 5.32$ \\
\hline
\end{tabular}

Table (7) demonstrated that, the majority (87\%) of the parents had children with ADHD were not competent. While, $(13 \%)$ of them were competent.

Table (8): Differences between parent's sense of competence and parent's socio demographic data

\begin{tabular}{|c|c|c|c|c|c|}
\hline \multirow{2}{*}{ Variable } & \multicolumn{5}{|c|}{ Parents sense of competence } \\
\cline { 2 - 6 } & $\mathrm{N}$ & NO\% & SD +Mean & $\mathrm{T}$ & $\mathrm{P}$-value \\
\hline Gender & Male & $36 \%$ & $5.73 \pm 56.3$ & 2.15 & $0.03^{*}$ \\
& Female & $64 \%$ & $4.91 \pm 53.9$ & & $0.032^{*}$ \\
\hline Job & Work & $20 \%$ & $5.14 \pm 57.1$ & 2.17 & 0.968 \\
& Not work & $80 \%$ & $5.24 \pm 54.2$ & & 0.368 \\
\hline History of & Found & $23 \%$ & $6.31 \pm 54.8$ & 0.040 & \\
disease & Not found & $77 \%$ & $5.03 \pm 54.8$ & & 0.905 \\
\hline Residence & Rural (83) & $83 \%$ & $5.37 \pm 55.1$ & & \\
& Urban (17) & $17 \%$ & $5.05 \pm 53.7$ & & \\
\hline
\end{tabular}


(Significant at *P<0.05 ).

Table (8) illustrated that, there were statistically significant differences between gender and job regarding parent's sense of competence $(\mathrm{p} \leq 0.03 \& 0.032$ respectively). While, there were no statistically significant differences between history of disease and place of living regarding parents sense of competence.

Table (9) the correlation between ADHD and parents stress and parents sense of competence (n=100)

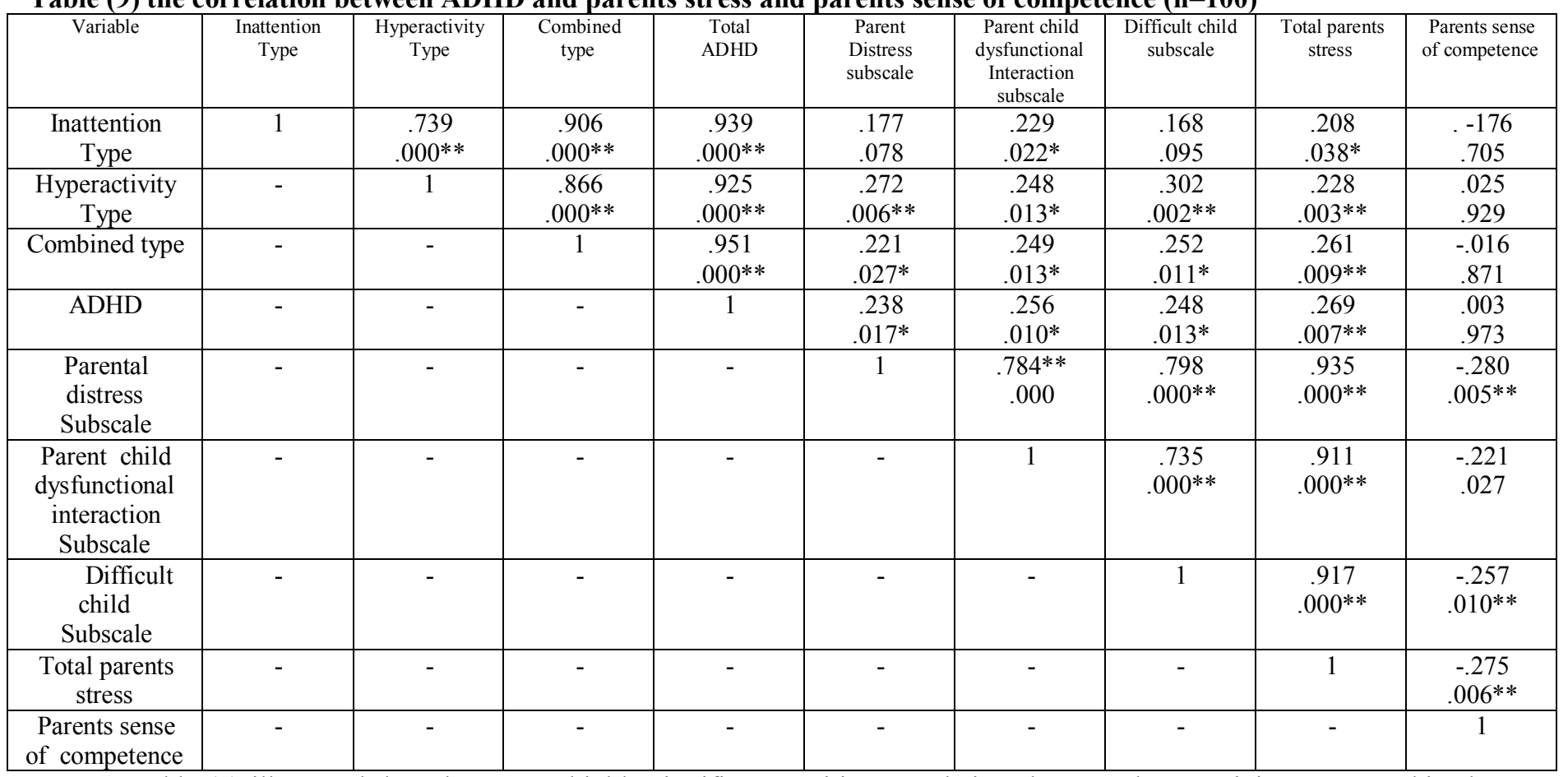

Table (9) illustrated that, there were highly significant positive correlations between hyperactivity type, combined type and total ADHD with inattention type. Also, there were significant positive correlations between combined type and total ADHD with hyperactivity type. Moreover, there were significant positive correlations between combined type and total ADHD.

In addition, this table showed that, there were highly significant positive correlations among subscales of parenting stress (parent distress subscale, parent child dysfunctional subscale, difficult child subscale) and all types of ADHD (inattention type, hyperactivity type, and combined type). At the same line, there were highly statistically significant positive correlations was found between total ADHD and total parent stress $(r=.269, \mathrm{p}=.007)$. while, there were highly significant negative correlation were found between parent's sense of competence and subscales, total parents stress.

\section{Discussion:}

As regards to socio-demographic characteristics of parents having children with $\mathrm{ADHD}$, it was found that, the highest percentages of the studied sample were illiterates, while secondary school and university education were lowest percentage (table 1). This might be due to the majority of the studied parents were living in rural area, were less knowledgeable about ADHD and with low educational level those factor were adversely affected their care and management of the ADHD child so; the children deteriorated to severe level of ADHD symptoms. This finding was incongruent with (17) who found that, the highest percentage of parents was average qualified, and the minorities of parents were illiterate. Also (18) found that, the highest percentage of parents was preparatory / secondary school education and the minorities of parents were illiterate.

Concerning the history of ADHD, the current study illustrated that, the majority of the studied parents didn't have a past history of attention deficits hyperactivity disorder (table 1). This might be due to that ADHD is the result of complex interactions between, genetic, developmental, neurological and psychosocial factors and the highest percentage of studied sample were mothers and their developmental history of pregnancy period and delivery process were normal and might be due to people didn't know difference between child normal hyperactivity and abnormal activity. In addition, the majority of parents still considering $P$ a g e | 120 child with ADHD stigmatizing their life so, they can avoid psychiatric treatment for fear of stigma. This result was supported by (19) who found that, more than three quarters of parents had a negative family history of ADHD, while less than one quarter had positive family history of ADHD.

Moreover, the current study represented that, more than three quarters of the parents $(79 \%)$ had $4-6$ of the family number (table1). This might be due to the nature of people in rural areas preferred to have more children and no family planning. This higher number of children was associated with more difficulty in the parenting role and lead to marital stress, increased financial burden, parents feel overwhelmed, guilt and worry by responsibilities of their children disability and mothers complain about the burden of caring toward their children of ADHD. This result was congruent with the study carried out by (20) who found in his study about (71\%) of parents had (4-6) of the family number. This finding was contradicted with the study carried out by (21) who found that, most of the sample (76.7\%) has family size of 1-3 numbers.

As regards to socio-demographic characteristics of ADHD children, the present study demonstrated that, more than half of children with ADHD were at the age group from $6-8$ years and were in first grade school (table, 2). It might be due to this age characterized by pervasive developmental changes and ADHD begin in early childhood and the main complain in this age is impulsivity, hyperactivity and lack of

Samia S., et al 
attention in duties of schools. This result also was consistent with the result of (22) \& (23) who reported that, the majority of children's age included in the samples were 7-8 years and the majority of the children were in first grade of school.

The present study demonstrated that, more than two thirds $(61 \%)$ of children had aggressive behaviors, while $(39 \%)$ had disruptive behaviors (table, 2). This result might be due to ADHD children often deal with a social rejection from peers and their neighbors. Parents and teachers often complain about not being able to control the behavior of these groups of children, may complain of their aggressiveness and refusal to follow rules. The children often feel not accepted by others so, their aggressive behaviors increased. This result was supported by (24) who found that, $(77, \vee) \%$ of children had aggressive behaviors while $(33.3 \%)$ had unstable behaviors.

Concerning the ADHD characteristics, the current study presented that, the majority of the children included in the study had combined type (ADHD), while the minority was predominantly inattentive type (Fig, 1) and more than three quarters of them had high level of ADHD according to the combined type (table,3). This result was supported by (25) who conducted a study about the prevalence of attention-deficit/hyperactivity disorder in Fayoum city (Egypt) among school age children found that, the combined ADHD subtype was the most prevalent. In the same line, this finding was in agreement with a study by (26) who conducted a study about the prevalence of attentiondeficit/hyperactivity disorder among primary school children found that, the combined ADHD subtype was the most prevalent, hyperactive-impulsive subtype was the second and inattentive was the third.

As regarding difference between parent's sociodemographic data regarding $\mathrm{ADHD}$, the present study indicated that, there was statistically significant difference between genders of the parents regarding ADHD and it was observed that the highest mean score of parents were among females (table, 13). This might be due to that mothers who were more frequently involved in their child care, spend more time taking care for their children and more aware of their symptoms and the effects of their behaviors. Also, mothers tried to cope with their children problems and were trying to get more information about the child disease.

This result was congruent with (27) who found that, there were significant differences between genders of the parents and ADHD children because of in modern life, the females have entered the workforce and working outside home in addition to their responsibility at homes and caring for their children. The current study was in disagreement with (28) who found that, the mean score of parents having children with ADHD was high in males than in females in his study. This might be due to that fathers commonly play the central figure of authority in the family and he is the one who take the principal responsibility for disciplining their child.

Regarding stress among parents having children with ADHD, the current study also demonstrated that, more than two thirds of the parents had high level of stress (table, 5). This result might be due to that the parents were afraid of failure of their children in their school due to their distraction and lack of concentration and most of them had feeling of sadness and depression for disturbance or disorganization at home caused by their children. This result was supported by a study carried by (29) who found that, the majority of parents have children with ADHD had high level of stress;

$P$ a g e | 121 physical, social, financial and psychological stress. In the same line (30), (31) \& (32) reported that, high level of parental stress is common in parents of children with ADHD.

As regarding difference between parent sociodemographic data and parent's stress, concerning the difference between parents' genders regarding parents stress, the present study result revealed that, there was highly statistically significant difference between gender and parents stress. It was observed that, the highest mean score of parent stress was among females (table, 6). This result could be due to that mothers take care for their children than fathers. Moreover, unacceptable behaviors of ADHD children and where the mothers display more negative reactions toward their children's behaviors and use more punishments to control their hyperactivity these behaviors lead to more parenting stress. This result was in agreement with (33)\& (34) who reported that, the mothers were more distressed than fathers, and that mothers are taking more responsibility in the upbringing and everyday life in families with a child with ADHD.

Regarding parents job, the present study revealed that, there was statistically significant difference between parents' job and parental stress, where parents who do not working had the highest mean score of stress (table, 6). This result might be due to that parents who are not working had low income, high financial cost of medications and the cost of visiting psychiatric clinics visits; additionally child's behavior might lead to increase of problems or conflict between husband and wife leading to disturbance in family functioning and marital stress. This result was in agreement with (35) who reported that, some mothers gave up their jobs to care for their children and to meet the demands of medical treatment for their children.

Regarding parent's sense of competence among parents having children with ADHD, the current study demonstrated that, the majority of the parents having children with ADHD were not competent (table, 7). This might be due to that the children with ADHD have greater pressure demands and efforts on their parents in addition to their duties toward the other siblings and home activity. Beside the attention of the parents was pulled in different directions toward the child with ADHD and other family members, parent's feelings of resentment by the child who requires more attention all these factors combined to create a parenting role that can quickly become overwhelming. This result was congruent with (36) who suggested that, parents of children with ADHD tend to consider themselves less competent in their role as parents.

As regarding relationship between parent sociodemographic data and parent's sense of competence, the present study also proved that, there was statistically significant difference between gender of parent and parent's sense of competence and the highest mean score of parent's sense of competence among male parents (table, 8). This result might be due to fathers' nature of responses to potentially stressful situations was different than mothers and become less stressful and more competent than mothers. This finding was supported by (37) who conducted a study about the relationship between parental stress, self-esteem and competency levels and their perception of their children's behaviours found that, statistically significant relationship between gender of parent and competency levels.

Regarding correlations between the study variable, the present study indicated that, there was highly significant positive correlation between ADHD and total parent's stress

Samia S., et al 
(table, 9). This result might be due to parents' responsibility to provide extra supervision and care at home, while managing more parental demands outside of the home. Beside children with ADHD experiencing frequent academic, behavioral and social problems at school with increased demands which frequently associated with more stress in marital relation with negative impact on parents' emotional well-being and family functioning.

This result was supported by a study carried by (38) who found that, there were highly significant positive correlations between ADHD and parent stress due to the mothers complain about the burden of care which includes the emotional burden of children's conditions and unable to do their discipline demands, thus causing frustration, anger and more strict demands placed on the parents and their children. Moreover, this finding was in agreement with (39) who showed that, there was significant positive correlation between ADHD and parent stress, found most of the parents reported having to care for their hyperactive child was their main reason for feeling stressful.

Concerning correlation between parent's stress and parent's sense of competence the present study reported that, there was highly significant negative correlation between parents competence and total parental stress (table, 19), this might be due to ADHD- related characteristics of the child uniquely produce stressors that adjust parent's behaviors, family function and the parents have to face more challenges to deal with noncompliance situations, school, peer and siblings difficulties. These difficulties can also lead to increased parenting stress and decrease parenting role. Parents may have a hard time dealing with the challenges that come with caring for a child with ADHD.

This result was in agreement with (40) who showed that, the experience of parenting is different (i.e. greater stress, lower feelings of competence) for parents who perceive their child to have greater behavior problems, when compared to those parents who perceive lesser behavior difficulties. In the same line (41) who found that, families with a child of ADHD feel more stressed, less effective and less satisfied, when faced with a child who displays elevated rates of problematic behavior and increased rates of maternal depression and negative feelings about parenting competence.

\section{Conclusions} concluded that:

Based on the results of the present study it could be

- There were highly significant positive correlations between total ADHD and total parent's stress $(p=.007) \&$ there were highly significant negative correlations between parents sense of competence and total parents stress.

\section{Recommendation:}

A structured psycho- educational program should be developed for parents having children with ADHD to increase their knowledge about caring and dealing with ADHD children.

\section{Reference}

1. Cortese, A., \& Ferrin, S., (2016). "Neurofeedback for Attention Deficit/Hyperactivity Disorder: Journal of the American Academy of Child and Adolescent Psychiatry. 55 (6): $\mathrm{p}, 444-55$.
2. Steinau, S., (2013). "Diagnostic Criteria in Attention Deficit Hyperactivity Disorder - Changes in DSM 5". Frontiers in Psychiatry. P, 4- 49.

3. American Psychiatric Association, (A.P.A). (2013). Diagnostic and statistical manual of mental disorders (5th Ed) P, 333-345.

4. Longobardi, F., \& Gastaldi, A., (2016). Examining studentteacher relationship from students' point of view: Open Psychol. P, 176-187.

5. Rogers M., (2015). ADHD symptomatology and the teacher-student relationship. Emot. Behav. Diffic. 20 p, 333-348.

6. Wingsiong, A., (2015). "Parentification, Coping, and Distress in Siblings of Individuals with and without Attention Deficit/Hyperactivity Disorder (ADHD)". P, 5468.

7. Kiely, B., (2015). "What we do not know about ADHD. Yet" 2014:257369 current opinion in Pediatrics. 27 (3): p, 395-404.

8. Esmaeilzadeh, K., (2014). Interactive vulnerability among families having children with ADHD: a Qualitative Study. International Journal of Academic Research in Applied Science 3(5): p, 34-43.

9. Salas M., (2015). Children's emotional and behavioral problems in the foster family context. J. Child Fam. Stud. $24 \mathrm{p}, 1373-1383$.

10. Bianchini, R., (2015). Prevalence of ADHD in a sample of Italian students, Research in Developmental Disabilities, 34, p, 2543-50. Google Scholar.

11. Avcil, S., Uysal, P., \& Biçer, C. (2017). Dynamic thiol/disulfide homeostasis in children with attention deficit hyperactivity disorder and its relation with disease subtypes. Comprehensive Psychiatry, 73, p, 53-60.

12. Farahat T., Alkot M., Rajab A., \& Anbar R., (2014). Attention-Deficit Hyperactive Disorder among Primary School Children in Menoufia Governorate, Egypt.

13. Abd_AlKarim, S., (2011). The prevalence of ADHD of school children in Minia city, Minia University, faculty of medicine.

14. Gorham, E., (1988). The Brief Psychiatric Rating Scale (BPRS), recent developments in ascertainment and scaling. Psychopharmacology Bulletin 24: p, 97-99.

15. Abidin, R., (1995). Parenting Stress Index (PSI) Manual, 3rd ed. Charlottesville, VA: Pediatric Psychology Press.

16. Wellston, K., (1978). Facets scales of social interaction and the social competence, Children's peer relations: Issues in assessment and intervention New York: Springer-Verlag P, 3-22.

17. Mahmoud, A., (2013). Parenting Stress and Self Esteem among Families of Children with ADHD in Pediatric Univeristy Hospital. Cairo Univeristy.

18. Fathy M., (2016). Burnout among Nurses Working in Psychiatric Hospital. P, 123-136.

19. Moawad, N., (2017). Stress and Coping Patterns among Parents of Children with Attention Deficit Hyperactivity Disorder, Faculty of Nursing, Ain Shams University.

20. Mitchell, m., (2014). Parents' stress and coping with their children's attention deficit hyperactivity disorder University of Maryland, p, 88-92. 
21. EL Nagar, S., \& Hamed, W., (2017). "Parents Adjustment for Caring of Attention Deficit Hyperactivity Children." American Journal of Nursing Research, vol. 5, no. 4 Pediatric Nursing, Menoufia University, Egypt.

22. Al-Mahmoud S., (2013). Effectiveness of Health Educational Program on Parents' Coping Strategies and their Children with Attention Deficit Hyperactivity Disorder.

23. Mohammad A., Seleem,U., Tarek, M., El-Gohary,E., Manal, A.,\& Eid, A. (2014). Serum Ferritin is Negatively Correlated with Inattention in a Sample of Egyptian Children with Attention Deficit Hyperactivity Disorder.

24. Sujata,S.,\& Raghu,H., (2014). Study of Level of Stress in the Parents of Children with AttentionDeficit/Hyperactivity/Disorder, Department of psychiatry, p, 21-23.

25. Aboul-ata,M., \&Amin,F., (2018). The prevalence of attention-deficit/hyperactivity disorder in Fayoum city (Egypt) among school age children, p, 11-15.

26. Alizadeh H., Armion E., Frederick L., Coolidge, D., \& Flores, A., (2015). The Prevalence of Attention Deficit/Hyperactivity Disorder among Primary School Students in an Iranian Rural Region, p, 23-45.

27. Bodewig,.C.,\& Badiani ,M., (2014).cognitive behavioral therapy for ADHD preparing the workforce for a modern market economy world bank publication.

28. 28- Hunt, C., (2014). Associations between Different parenting Styles and Child Behavior, PCOM Psychology Dissertations. P, 258-262.

29. Bussing, R., \& Mehta, S., (2015). Stigmatization and selfperception of youth with attention deficit/hyperactivity disorder. P, (15-27).

30. Viduoliene, E., (2013). Predicting the change of child's behavior problems: socio-demographic and maternal parenting stress factors. Social Transformations in contemporary Society, p, 267-276.

31. Van Steijn. J., Oerlemans. M., van Aken. M., Buitelaar. K. \& Rommelse. J. (2014). The reciprocal relationship of ASD, ADHD, depressive symptoms and stress in parents of children with ASD and/or ADHD. Journal of Autism and Developmental Disorders, p, 44-76.

32. Khodabakhshi, K., Shahi A., Navidian A., \& Mosalanejad L., (2015). The effect of positive parenting program training in mothers of children with attention deficit hyperactivity on reducing children's externalizing behavior problems. Journal of Fundamentals of Mental Health p, 135-141.

33. Theule, J., (2013). Predicting parenting stress in families of children with ADHD. Unpublished thesis for the degree of doctor of philosophy. University of Toronto.

34. Beecroft, A., (2013). The faculty of the Adler school of professional psychology.

35. Factor, L., \& Sziba, D., (2015). Self-esteem and stress of parents with ADHD children,P, 166-178.

36. Stefanini R., Pires A., Arthur E., Cavalin A., \& Guazzelli S.,(2015). Adolescents with attention deficit hyperactivity disorder and exposure to violence: parents'opinion. P, 1090-96.

37. Eanes, A., \& Fletcher, A. (2014). Factors associated with perceived competence among special needs adoptive mothers. Families in Society, p, 249-258.

38. Hrriazni, L., \& Alkaissi A., (2016). The Experience of Mothers and Teachers of Attention Deficit / Hyperactivity Disorder, and Their Management Practices for the Behaviors of the Child. Journal of Education and Practice Vol.7, No.6.p, 44-48.

39. Narkunam N., Hashim A. H., Sachdev K., \& Pillai K., (2014). Stress among parents of children with attention deficit hyperactivity disorder, Asia-Pacific Psychiatry: Official Journal of the Pacific Rim College of Psychiatrists, 6(2), p, 207-16.

40. Chelsea, D., (2013). Parenting a child with behavior problems Journal of Education and Practice ISSN 22231737 (Paper) ISSN 2223-288X (Online) Vol.7, No.9.p, 2233.

41. Hannah, B., (2014). Child behavior, parent-child relationships, and parental self-esteem in families with a child ADHD department of psychology 